\title{
OPPORTUNITIES AND SOLUTIONS TO MODERN IMPROVEMENT OF BULGARIAN CONTROL
}

\author{
Venelin Terziev ${ }^{1}$ and Evgeniy Stoyanov ${ }^{2}$ \\ ${ }^{1}$ Professor, Ph.D., D.Sc. (National Security), D.Sc. (Ec.), University of Rousse, Rousse, Bulgaria; \\ National Military University, Veliko Tarnovo, Bulgaria; University of Telecommunications and Post, \\ Sofia, Bulgaria, terziev@skmat.com \\ ${ }^{2}$ Professor, Ph.D., D.Sc., National Military University, Veliko Tarnovo, Bulgaria
}

\begin{abstract}
This article studies the phenomenon "control”, manifested in the functioning of the Bulgarian socio-economic environment. The reason for the development is the fact that in theory and in discussions there is control but there are no real results adequate to the needs of society. The purpose of the study is to reveal, at least theoretically, the cause of this condition. The object of the research is the development and model improvement of specific and well-established concepts, the control models they are based on, and the probability of their effective and close interaction. The specifics of the selected topic suggest and predetermine the use of mainly analytical and retrospective methods.
\end{abstract}

Keywords: control, concept, unified process, management control, model

\section{INTRODUCTION}

The evolution of human society and the analysis of the results in its development prove that control as a phenomenon can by no means be interpreted as a manifestation of certain circumstances or materialized randomness. Permanent presence and continual improvement prove that this social phenomenon has acquired the quality of a mandatory requisite in the social system. The sources that have predetermined the specific characteristics and essence of control are several. First of all, control is a critical public attitude. Second, it is not only present but also revises the results of the work of each management process. Third, the building and consolidation of each social structure proves that the processes of governance, organization and functioning are fixed within certain frameworks, i.e. the observance of powers by law requires and imposes control. Last but not least, the work of the state, interpreted as a higher institution and a supreme institutionalizing organization, shows that efficiency is involved in the administration of all ongoing processes, but also with the implementation of administrative control included in the obligations of the executive authority. 
Although, with regard to the State, it is expressed the view about the development of supervisory activity, we can actually and convincing say that this is a form of State control exercised by the state where in most cases imperative adjustments are made to the behavior of control objects, regardless of their status and institutional nature. In this sense, it is generally clear that the phenomenon of control has a strong justification that guarantees a significant social presence and potential for wide and effective application. Adding its principle start and growing expectations of society, it becomes clear that control is a key mechanism used by the societies to achieve success in every venture.

Although all the above-mentioned characteristics are present too in the development of the control in Bulgarian conditions, some more strokes can be added to the existing literature.

One of the peculiarities is that Bulgarian control has a sufficiently long history in which the leading role of the state and the presence of statehood and institutionality are established for the improvement of the applied control and its forms.

Another substantial detail is the presence of weak statehood accompanied by the registered large fragmentation of ownership, which is why control until the middle of the XX century develops mainly on the operational financial level, although there are many control subjects in the Bulgarian economic space.

The next feature is that due to the change of the planned market economy, all economic processes and tendencies characterized with a delay of $15-20$ years in the Bulgarian economic reality. Adding the global economic crises, it becomes clear that the functioning of the national economy is taking place in a dynamic and at the same time „difficult” environment.

A very important factor influencing the development of Bulgarian control and stemming from the previous features is that the lack of a stable economic environment provokes frequent changes in the legal framework and hence the almost unpredictable behaviour of a large part of the economic subjects. This is due to the lack of efficiency in control and, above all, the establishment of prevention against the increasingly frequent deviations in the work and behaviour of a large number of control sites.

Under these conditions and the circumstances that have arisen, it is interesting that the concept of control as a theoretical development in the past 20 years registered a significant growth. In practical terms at macroeconomic level, the control is marked by serious development and significant institutional presence.

But the problem of the society and the state is not that control is not exercised, but that the economic entities that are expected to work and produce, operate with increasing difficulties, said in other words, at microeconomic level the results are not good. Although the number of reasons for this are big enough and varied in character, and in particular control does not show the necessary efficiency. In this context, managers and consultants are particularly interested in the purely controlling part of the problem. On a conceptual level, aware of the deficiencies of the individual control forms manifested in their interaction both scientific thought and business and practice representatives focus their attention on management control as consolidating in its model manifestations the good opportunities of all known and proven forms on the one hand and at the same time compensating registered gaps and weaknesses on the other.

Analyses prove that most of the last century was dominated by a conception where management control was seen exclusively within the operational and operational and tactical management of organizations (1998) By the end of the century, the concept of the three-element structure of management control, such as control over implementation, operational-tactical and strategic control, was firmly established.

The review of existing concepts about the state and development of management control in modern organizations gives grounds to make the following assessments in several respects (2009)

The starting point is the fact that as a result of the development of economic and management science at the end of the twentieth century a high degree of maturity of the theoretical concepts of control as a function of management was achieved. This degree of maturity has allowed the establishment of control theory as a significant independent branch of scientific knowledge of management. The analysis of the concepts of the Bulgarian researchers and their presentation in a summarized form in a standard for the control process shows that they fully correspond to and are confirmed by leading Western studies. Moreover, the comparative study on the degree of specificity and interdisciplinarity of the control process model developed in Bulgaria shows that this model takes a leading position among the known foreign views.

It is important to note that the modern world puts the implementation of management control under new conditions that change the accents, the degree of importance and priority in integrating the elements of the control process. These new conditions are above all the expression of dynamic, radical and unexpected changes in the environment of organizations. The new state of the environment leads to a rethinking of the concepts of management control as a manifestation and realization of the principle of feedback. Without 
IJASOS- International E-Journal of Advances in Social Sciences, Vol. III, Issue 8, August 2017

losing its role of negative feedback, ensuring the implementation of performance standards in organizations, management control increasingly enhances its role of positive feedback, leading to change in targeting and planning of activities. In this sense, the emphasis on the study of the sanctioning functions of control within the views of the "controlled organization” towards the end of the $20^{\text {th }}$ century radically moved to the study of its transformation into a factor for generating ideas for change within the framework of the views of the „innovative organization". The essence of this trend tends to be seen as a "first pillar" in the further development of managerial control concepts.

It is particularly interesting to emphasize that entering into the new knowledge and information economy alters the key success factors of organizations. Over the last years of the old and the first years of the new century, the notion that the underlying role of these factors is the growing role of intangible assets has been strongly reinforced. This has put management control in a situation requiring the theoretical understanding of the methodological and methodical level of new trends and methods for measuring the norms of the systems, their actual and expected state, as well as the diagnosis of the deviations. There is a clear tendency to expand the circle of controllable financial parameters in the direction of intangible ones and the consequent deepening of the interdisciplinary nature of the control theory. The current trend can be interpreted as a "second basic pillar" in the modern development of the management control theory.

Towards the end of the twentieth century, the emphasis in the study of strategic control issues began to turn into a central issue in enhancing knowledge about management control. Various ways and means are sought so that the theoretical systems of performance control and operational-tactical control to be integrated strategic control systems (2005a) The registered trend may be considered to be a "third basic pillar" in the further development of scientific knowledge on management control.

The development of the above mentioned trends in the development of the management control concept influences the main forms of control manifestation both globally and in Bulgaria. This is what makes it necessary to analyse briefly both the models and systems of managerial control themselves and their potential for development and consolidation.

The improvement of management control systems in the twentieth century, studied through the prism of this work's goals and tasks, makes it possible to make a few summaries of the specific forms or models possessing characteristics to be recognized as models implementing the idea of management control.

The fundamental scientific approach to the study of the management control system as a set of elements, objects, entities and tools, the relationships and interactions between them, preserves its fundamental importance in scientific research. At the same time, especially in the second half of the twentieth century, the role of scientific and applied research, which is focused on particular aspects and areas in the development of the structure of the management control systems, is growing. This builds on existing concepts of these systems as systems with predominantly operational production and technological focus, which have as their object exclusively the material parameters of the functioning of the organizations. Towards the end of the century, new conceptual views on the development of operational-tactical and, to a certain extent, strategic aspects of management control systems have been largely shaped in theoretical and practical terms, which are mainly related to changes in the views of the object area of control and the tools used.

Leading importance as a degree of theoretical development and practical applicability in the second half of the twentieth century has the budget control systems that provide the needs of operational and tactical management. Budgetary control is established as a central unit of the management control systems and subordinates to its development the control over the implementation of the activities. The development of budgetary control systems and their organic integration with activity control systems is strongly stimulated and facilitated by the emergence and consolidation of modern management information systems. The gradual upgrading and creation of the technical and programming prerequisites of the ERP systems creates the necessary conditions for this by providing the possibility of facilitated and timely integrated operational and operational-tactical control over the meanings of the material and value parameters of the functioning of the organizations and over the increase of their value (2013)

Towards the end of the twentieth century, the views about the budgetary control systems purposefully seek to cover also the strategic aspects of the organization's development by including in their structure elements of strategic budgetary control. However, this is, as a rule, based on attempts to integrate budgetary control over the value and material parameters of organizations. To a large extent, this approach is influenced by the state of ERP systems that, until the first years of the new century, are exclusively focused on the management and control of material and monetary resources. This contradicts the need to control the acquisition of new success factors, which in the age of knowledge and information are predominantly nonmaterial. In this sense, the limitation of the budgetary control systems as a strategic control tool becomes more and more obvious and raises the need to develop and implement other types of strategic control 
modules in management control systems.

The tendency to focus on the development of operational-tactical aspects of management control systems, incl. mainly on the basis of budget control and ERP systems, finds a strong expression in the emergence and consolidation of the concept of controlling (1997) Contrary to traditional views on budget control, this concept sets in its foundation the overall organic unification of the implementation of planning and control functions and ensuring the targeted development of organizations. A key condition for this unification is the emergence of management control as a timely positive feedback and a goal-setting factor in the unified planning and control process. At the same time, the concept of controlling makes a significant theoretical and practical attempt of establishing a complete institutional structure of operational and operational-tactical planning and control systems, including for the location of specialized controlling subjects in organizational structures. The development of strategic aspects of control systems by the end of the last century remains largely at the level of principle and also develops mainly in terms of encompassing traditional factors of value growth.

An important area in the development of the strategic aspects of management control systems in the second half of the $20^{\text {th }}$ century is the problem of project control. The source of this is the shaping of project-oriented management as an independent area of the theory and practice of social management. This leads to the upgrading of operational-tactical management control systems with project control modules that ensure the implementation of strategic projects. However, these modules are, by definition, partial in nature, help to make separate strategic breakthroughs without fully embracing the process of developing and implementing the organization's strategy. Again, as with budget control systems and controlling systems, the overriding priority of project control systems belongs to the material and value controllable parameters. (2011)

Although the strengths of the concept of management control and of its basic model (systemic) manifestations have been established and proven, the operation of the Bulgarian economic entities seem to be deficient such manifestations of larger scale. The definition of "large scale" is seen in the context of precisely those models or systems that cannot only control but above all create conditions for building synergies and upgrading between traditionally applied systems, while in the same time allowing a meaningful rethinking of control in new and more meaningful and promising trends.

Specifically, as in the rest of the world, the concept of a balanced scorecard also makes fragmentary breakthroughs in the Bulgarian economic realities. Based on the registered results and established weaknesses of the traditional management control, the prerequisites for the emergence of the idea of balanced assessment scorecards are considered. The scorecards themselves are defined by their creators as a set of strategic perspectives, key factors and indicators of success, target values of indicators and initiatives to achieve them, which collectively represent the strategy of the organization (1996) The role of highlighting the different perspectives (finance, users, internal business processes, training and development) for the complex assessment of the organization from the point of view of the main stakeholders is emphasized.

Analyses of the results of the small number of scorecards working in Bulgarian enterprises and organizations show that attention is focused on the role of the study of cause-and-effect dependencies in highlighting the most important in the development of the organizations 15-20 indicators in total for all perspectives. This role is seen as a basis for turning the scorecards into a synthesized strategy that is crucial to their validation as a tool for implementing and controlling the strategy.

Particular attention is paid to the need to individualise the approach to developing and implementing scorecards in line with the state and visions of organizational development. The opinion is shared that „a balanced scorecard is not a template that can be applied generally to different types of business or even to a whole industry. Different market situations, product strategies, competitive environment require the use of different scorecards. Business units create individual cards, corresponding to the mission, strategy, technology and culture“. (2000)

Specifically, under Bulgarian conditions, working with the balanced scorecard model marks two development trends.

One continues the conceptual line of maximum convergence between the concept of management control and the "classic" balanced scorecard (the model created by Kaplan and Norton). The critical review proves that the model of balanced assessment cards, while recognizing the dominant role of value-for-money theory in business organizations, in a way respects the leading role of the perspective of finance. Fundamental importance for structuring the model for each organization is the study of causal relationships and dependencies between indicators from other perspectives and those from the perspective of "finances". Unlike previous management models, however, the model of the balanced scorecard includes in these 
relationships a considerably wider range, mostly intangible indicators. In this sense, the model radically „builds" primarily on the financial models and achieves a more complex coverage of the factorial conditionality of the organizations' success in the knowledge and information economy.

The other focuses on developing and improving quality, i.e. continues the development trends developed by Rampersad (2005b). The coverage of a wide range of non-material factors of organizational success requires the introduction of new types of systems to measure the intangible performance of organizations in management practices. Towards the end of the century, this stimulated the active development and implementation of modern methods to measure the satisfaction and loyalty of clients and staff, the development and evaluation of intellectual capital, etc. At the same time, in the management practice, methods are emerging, merely used by them, for studying relations and dependencies of correlation type.

Although, according to the above lines, it can be considered that in theoretical terms control, management control and models in Bulgaria are written and spoken of, the situation in Bulgarian practice is not adequate.

At this stage in the public sector, financial control and mainly the work with its budgets or budgetary frameworks in the best case have a leading role. The application of ERP or controlling systems is discussed and used mainly in sectors with non-Bulgarian owners and predominant presence of high-tech solutions. With regard to project control, things have gained new dimensions in recent years because project finance has become a key to business survival in a number of cases, and because society has already reacted sharply to all kinds of abuse.

Regarding the balanced scorecards and similar large scale model solutions to ensure good management and effective control, it is clear that desire is not lacking, but the key to the success of their development and implementation is subjective. The issue of control over scorecard development and implementation processes again highlights the problem of the lack of specialized information and analytical units in the organization to support senior management in this process. The necessary reassessments of both the planned meanings of indicators and of themselves and even the main perspectives of the scorecards in the process of their implementation require efforts that are comparable to those of their development and implementation. In this respect, the attempt to develop and implement a balanced assessment scorecard in Bulgarian conditions strongly confirms the foreign assessments that the commitment of the top management of the organization and the building of the relevant information and analytical infrastructure are a basic prerequisite for the implementation of this process.

The content of the expose proves that in the Bulgarian economic conditions there are theoretical prerequisites for putting into use different control and control models, which can even be unified and set up a unified large-scale organizational system like the balanced assessment scorecard. The real opportunity for this is only effective management to become a real art, and the control to be established as a conscious necessity of all the layers of the Bulgarian society, serving the goals of the government and the interests outlined by society.

\section{REFERENCE LIST}

Kaplan R., D. (1996). Norton, The Balanced Scorecard: translating strategy into action, Boston.

Han D., (1997). Planning and Control: Concept of Controlling (Translation from ger,m), Moscow.

Antony, Dearden, Govindarajan, Management (1998). Control System, H.

Ehrmann H., (2000). Kompakt - Training Balanced Scorecard, London.

Stoyanov E.N., (2005a). One Successful Strategic Control Idea, Bourgas, Anthey-TH.

Rampersad, H., (2005b). The universal system of performance indicators, Alpina, Moscow.

Stoyanov E.N., (2009). Management Control Systems, Burgas, Libra Scorpion.

Stoyanov E.N., (2011). Project Management and Control, Libra Scorpio, Burgas.

Stoyanov E.N., (2013). Theory of Financial and Economic Analysis, Burgas, Libra Scorpio. 